\title{
El niño judío reloaded: Un milagro reescrito desde el Siglo XXI
}

The jewish child reloaded: A miracle rewritten in the 21th Century

Mauricio Toro mauriciotorocea@gmail.com

Universidad de Chile

\section{Resumen}

En este trabajo se presenta un nuevo poema basado en el milagro "El niño judío" de Gonzalo de Berceo, original del siglo XIII.

Palabras claves: Literatura española - Milagro - Exemplum - Poesía - Estereotipos.

\begin{abstract}
In this paper, a new poem based on the Gonzalo de Berceo's miracle "The jewish child" is presented.
\end{abstract}

Key words: Spanish literatura - Miracle - Exemplum - Poetry - Stereotypes.

\section{Poema "El niño judío"1}

La obra más célebre de Gonzalo de Berceo es "Los Milagros de Nuestra Señora”. En ella se encuentran veinticinco relatos religiosos versificados, pertenecientes al sub género lírico de "milagros", escritos en el siglo XIII. Estos milagros están basados en otros relatos anteriores, los exempla, los cuales eran pequeñas narraciones utilizadas por los

${ }^{1}$ Campos (2012) estudia en profundidad la imagen del judío en la literatura española. En las páginas 253-263 se aborda la obra de Berceo. 
predicadores en sus sermones con el fin de ilustrar verdades teológicas de forma más sencilla y divertida para su audiencia.

Berceo se destaca por su prodigioso manejo con las palabras, logrando contar, bajo una estricta métrica alejandrina, las maravillas y bendiciones que da la Virgen María a sus devotos. Ella es la principal figura de sus poemas, fruto del marianismo recalcitrante de Berceo, imperante en esos tiempos. Con una primera lectura de estos poemas es claro ver que la intención principal de su autor es transmitir esta devoción, dando razón a la belleza, bondad, santidad y justicia que habita en La Señora.

El poema XVI de Los Milagros de Nuestra Señora, "El niño judío”, es el que motiva este trabajo. Este poema narra el exemplum en que la Virgen salva a un niño judío de ser quemado en un horno, frustrando el actuar del padre judío que pretendía asesinar a su hijo luego que éste recibiera la comunión; la historia termina con el padre judío arrojado al horno por quienes presenciaron el milagro. La versión utilizada de este poema, en castellano moderno, se encuentra en el apartado de anexos ${ }^{2}$.

\section{El padre judío}

En este milagro, el padre judío cumple un rol antagónico. El judío es malvado; cuando se nombra al judío se utilizan adjetivos que resaltan su maldad: "el malaventurado", “el endiablado", “el falso descreído", "falso y desleal”. Además, se dice que "se desfigura como un endemoniado” y se le maldice: “¡Maldito el que así trata a su hijo querido!”. Mientras el padre judío se quema en el horno, las personas presentes lo llenan de insultos, celebrando su muerte:

Decían mil maleficios y hacían mala ofrenda,

\footnotetext{
${ }^{2}$ Todas las citas de "el niño judío" han sido extraídas de Berceo, G. (1974). Milagros de Nuestra Señora. Santiago: Nascimento.
} 
y en vez de PATER NOSTER: "Quien tal hizo, tal prenda,

que de su compañía el Señor nos defienda

y que le dé al Demonio su fortuna y hacienda.

\section{La Virgen, hermosa Señora}

La Virgen María es la protagonista del milagro; por su bondad interfiere en los planes del padre judío, salvando la vida del buen infante. La belleza de la Señora contrasta con la fealdad del judío, el cual "se desfigura como un endemoniado". En los siguientes versos se lee la primera aparición de la Virgen en el poema.

Mientras que se encontraba en esa coyuntura,

el muchacho judío miró arriba, y a esa altura,

encima del altar, vio la hermosa figura

de una bella señora con una creatura.

En el resto de sus apariciones, se destaca en la Virgen su belleza y que carga al niño Jesús en brazos. Berceo concluye la historia exaltando la justicia de la Señora, dedicándole una alabanza.

Así es Santa María, la de gracia plena,

Capaz de darnos premios como de darnos pena;

A los buenos, el trigo; a los malos, la avena.

Los unos van en la gloria; los otros, en cadena, 


\section{La nueva versión}

La historia da triste testimonio del poder destructivo que tienen los prejuicios y estereotipos. Deicidio, libelos de sangre, envenenamiento de pozos, origen de la peste negra... estas acusaciones hacia el pueblo judío fueron semilla de odio, cuyos frutos han sido reiterados pogromos, expulsiones y el Holocausto.

Al cursar el diplomado en cultura judía en la Universidad de Chile, he tomado conciencia de los estereotipos presentes en la literatura española sobre el judío. Quien lea en la actualidad el milagro del niño judío pensará que es humor negro o una broma; sin embargo, la sola lectura del poema de Berceo no es suficiente para tomar conciencia del peligro que hay en estos estereotipos. Esta nueva versión del milagro fue escrita como un palimpsesto ${ }^{3}$, destacando y evidenciando el absurdo, con lo que se espera llevar al lector a una nueva lectura crítica del exemplum. Por lo mismo, la alusión a los frutos del prejuicio (pogromos, Holocausto) es directa.

A continuación se presenta el poema escrito. Para su redacción, y en vista de la lectura del poema original, se quiso caricaturizar la imagen negativa del padre judío, exagerando los estereotipos clásicos que circulan alrededor de él, tanto en su forma física como en su perfil psicológico. También se quiso dar una vuelta en la conclusión que entrega este exemplum: en lugar de terminar alabando a la Virgen, el hablante lírico, confundido, termina alabando al horno.

Se incluyeron elementos propios de la cultura popular contemporánea: la mención a Miguel Bosé y a la sátira religiosa con el dios de Spaguetti que levita con albóndigas de carne. Estos elementos son reflejo de que éste ya no es la reproducción de un poema del siglo XIII, sino que es un relato nuevo que busca contar un exemplum bajo la pluma y mirada de

\footnotetext{
${ }^{3}$ Es interesante como aborda Borges (1939) la composición de obras derivativas. Este nuevo poema del niño judío intenta llevar al lector a una experiencia de lectura como la que tuvo en la ficción de Borges Pierre Menard, quien es tan autor del Quijote como Cervantes.
} 
un joven chileno del siglo XXI.

El título del poema (que está sujeto a cambios) es una referencia a la película "Matrix Reloaded", otra alusión a la cultura popular contemporánea.

\section{El niño judío reloaded}

Cuenta así la historia,

lo juro que es cierto,

que triste memoria

relata este cuento.

El protagonista:

un niño precioso,

creación de artista

Todopoderoso.

Seis años tenía

niño muy bonito

si hasta parecía

ser un angelito

Ojitos de Cristo

nariz de San José

labios de San Sixto

voz de Miguel Bosé.

Pero esta belleza

era inexplicable, su padre era de esa 
gente abominable:

Curcuncha su espalda, su nariz torcida, barbas desaseadas, padece del sida.

"Judío usurero" suena redundante; hijo del postrero, del demonio errante.

No donaba el vuelto al supermercado "dos pesos no suelto, eso es gran pecado".

Oficios variados posee este perro: ladrón, abogado, prestamista férreo.

Mas dice el relato sobre este rastrero que emprendía a ratos labor de vidriero.

Ya basta de hablar tanto del judío, vamos a escuchar 
del infante pío:

El niño crecía

tan lleno de gracia

que hasta parecía

no ser de su raza.

Jugaba en las calles

con otros niñitos,

es este detalle

su falso delito.

Los niños cristianos

le hablaban de Cristo.

Juntos, de la mano,

rezaban a Cristo.

Los acompañaba

también a la escuela;

el cura enseñaba

a leer, con cautela.

¡Qué niño más listo!

Pensó el sacerdote

que nunca había visto

niño con sus dotes.

Hablaron por horas

de Dios y La Virgen,

rodeados de auroras, 
amor de La Virgen.

Tal como lo hizo

Jesús en su infancia,

el niño deshizo

todas las falacias.

Adultos silentes

oían pasmados

¿de dónde esta mente

aquello ha sacado?

Les dio teología

de la más sagrada,

sin saber sabía

la Historia Sagrada.

Así pasó el día

Domingo de Pascua,

el niño sentía

renovar su ascua.

Y dieron las siete,

hora de la misa.

Su corazón siente

deseos de misa.

Su padre lo espera,

el niño lo sabe.

Tirita su pera 
"Que Dios hoy me salve".

Se hizo obediente

a la voz celestial

y desobediente

al padre terrenal.

Se quedó en misa

feliz y asombrado,

grande es su sonrisa

él todo ha logrado.

Vio entonces las manos

de Dios hacia el mundo

limpiando al profano

limpiando al inmundo.

Era un Dios hermoso:

spaguetti santo

levitando en trozos

de albóndiga encanto.

Y vio una señora

de hermosa figura

rodeada de aurora,

de amor y dulzura.

Deseó comer hostia,

probó del Cordero,

en aquella hostia 
se dio por entero.

Paseó por el cielo

de spaguetti y nubes, pero hacia el suelo baja cuanto sube.

Caminaba a casa con mucho retraso. Su padre las brasas prendía al ocaso.

Su padre indignado al verlo llegar comenzó embriagado a vociferar:

“¡Oh! Pequeño infame vi lo que hoy hiciste, que el fuego te inflame pues tú lo pediste”.

Le ató con sus ropas de brazos y piernas, le bañó de copas con sangre de hienas.

Lo hizo pisar heces

con los pies descalzos "esto te mereces 
por dar malos pasos".

Entonces, tomando a su hijo en brazos

lo arrojó, llorando, al fuego y sus trazos.

Dios, que es Poderoso, milagros haría; el fuego tortuoso no lo quemaría.

(Mas tengo la duda ¿fue Dios o la Virgen el presto a la ayuda, del milagro origen?)

El padre asombrado gritaba de miedo, gritos que han llamado a todo Toledo.

(Compadre, ique es chanta!

- me dijo Berceo-

el exemplum canta

Bourges, no Toledo.)

Todos presenciaron este gran prodigio:

los santos salvaron 
al niño prodigio.

Sin dudar la gente

presente en la escena

fue muy diligente

en dictar condena.

"Que el fuego consuma

a este miserable

por toda su suma

de actos detestables"

El fuego infalible

quemó sin problemas

aquel cuerpo horrible

del perro anatema.

Fue quemado el padre

por su gran pecado,

y el niño y su madre

fueron bautizados.

Así ha terminado

esta triste historia

de sangre, pecado,

dolores y gloria.

De un niño perdido

que siente es su culpa

lo que ha ocurrido... 
De Dios no hay disculpa.

"Por mí es que ha muerto

mi padre. Sus hijos

lo lloran. Lo siento.

al Sheol me dirijo.

Vi cómo, entre insultos,

coreaban su muerte, sin darle el indulto

la cristiana gente."

Insultos que fueron

luego un holocausto,

los pogromos hirieron

a aquel niño santo.

\section{Cantemos con gozo}

por su gran bondad:

horno milagroso

quien tuvo piedad.

Protege a los buenos,

a los que son fieles,

mas da el fuego eterno

a hombres infieles.

Horno bendito

cuidaste al infante

en ti no hay delito 
voy a venerarte.

Salve, horno - digo-,

gratia plena, santo,

mirad, os bendigo

en gozo y quebranto.

\section{AMÉN.}

\section{Conclusión}

Si bien ya no se vive en el medioevo, en la cultura occidental aún persisten los estereotipos negativos sobre los judíos. Al mutar el final del texto original se modifica su enseñanza: continuar viendo al hebreo desde el prejuicio histórico es tan absurdo como alabar al horno al final del milagro. El fin de este exemplum ya no es adoctrinar -el tiempo se encargó de despojar de su poder a estos discursos líricos-, sino mas bien liberar al lector de las enseñanzas antisemitas que por siglos han sido transmitidas en la tradición literaria española.

\section{Bibliografía}

Alfonso X, R. d. C., \& Real Academia Española. (1990). Cantigas de Santa María. Madrid: Real Academia Española.

Berceo, G. (1974). Milagros de Nuestra Señora. Santiago: Nascimento.

Borges, J. (1939). Pierre Menard, autor del Quijote. Nîmes.

Campos, J. (2009). La errancia judía en la novela contemporánea hispanoamericana. 
Universidad de Chile. Disponible en http://tesis.uchile.cl/handle/2250/108578

Campos, J. (2012). El judío en la literatura española. Cuadernos Judaicos $N^{\circ} 29$, 240-296.

Dubnow, S. (1977). Manual de la Historia Judía. Buenos Aires: Sigal.

Engel, D. (2010), What's in a Pogrom? European Jews in the Age of Violence. En DekelChen, J., Gaunt, D., Meir, N. M., Bartal, I.(2011). Anti-Jewish Violence: Rethinkingthe Pogrom in East European History. Bloomington: Indiana University Press.

Amossy, R.,Herschberg P. (2001). Estereotipos y clichés. Buenos Aires: Eudeba.

Forster, R. (1999). El exilio de la palabra: En torno a lo judío. Buenos Aires: Eudeba.

Le Goff, J. (1986). El judío en los exempla medievales. El caso del Alphabetum Narrationum. En Lo maravilloso y lo cotidiano en el occidente medio. Barcelona: Gedisa.

Sánchez de Vertical, C. (1961). Libro de los exemplos por a. b. c. Edición crítica por John Esten Keller.

Vocabulario etimológico / por Louis Jennings Zahn. Madrid: Consejo Superior de Investigaciones Científicas. 


\section{Anexo}

\section{$\underline{\text { Milagro XVI El niño Judío }}$}

Fue en Bourges, una villa que se halla en tierra extraña

en donde sucedió tan prodigiosa hazaña

de fuerte resonancia en Francia y Alemania, que merece contarse. Es verdad que no engaña.

Fue escrito este milagro por un monje sincero del claustro San Miguel, del que era personero, y que por ese tiempo actuaba de hospedero.

Era su nombre Pedro: De eso estoy bien certero.

En la misma ciudad -porque era menesterun clérigo atendía una escuela de leer y cantar, para quienes deseaban aprender, hijos de buena gente y de mayor valer.

Un niñito judío, natural del lugar, para unirse a otros niños con el fin de jugar, venía a aquella escuela además de estudiar, acogido por todos también a conversar.

El domingo de Pascua, a la hora temprana en que recibe Cristo la población cristiana, de comulgar sintió él también mucha gana. Comulgó con los otros el cordero sin lana.

Mientras que se encontraba en esa coyuntura, el muchacho judío miró arriba, y a esa altura, 
encima del altar, vio la hermosa figura

de una bella señora con una creatura.

Vio que la hermosa dama que en ese sitio estaba

era la que a los grandes y chicos comulgaba,

y se sintió feliz. Cuanto más la miraba,

de su gran hermosura mucho más se prendaba.

Salióse de la Iglesia feliz, reconfortado,

y regresó a su casa como estaba habituado.

Lo amenazó su padre por haberse atrasado,

por lo que merecía que fuera castigado.

"Padre -le dijo el niño- no he de negaros nada,

pues con los cristianillos me fui de madrugada,

y con ellos oí una misa cantada,

y comulgué con ellos de la hostia sagrada"

Al oír esto, el padre, el malaventurado, sintió como si su hijo se hubiese degollado.

De ira, no sabía qué hacer el endiablado

hasta desfigurarse como un endemoniado.

En su casa tenía ese perro traidor

un gran horno que a todos producía pavor,

el que lo hizo encender el loco pecador

de modo que expidiera espantoso calor.

Tomó enseguida al niño el falso descreído, y así, tal como estaba, con calzado y vestido, 
lo arrojó en aquel fuego fieramente encendido.

¡Maldito el que así trata a su hijo querido!

Dio la madre - espantada- voces despavoridas

dañando sus mejillas con profundas heridas

frente a la multitud de gentes reunidas,

que viendo aquel horror estaban aturdidas.

Pero el fuego, aunque bravo, tuvo comedimiento,

y al niño trató bien el terrible elemento,

que en el horno se hallaba muy tranquilo y contento.

Dios fue el maravilloso autor de este portento.

Mientras estuvo el niño en el horno, su faz

era la del que en brazos maternos está en paz.

Para él, ese fuego sólo era otro rapaz.

La Gloriosa le daba compañía y solaz.

Salió el niño del fuego, intacto, sin lesión, sin sufrir más calor que el usual y en sazón, sin quemadura alguna y sin tribulación, pues Dios había puesto en él su bendición.

Todos le preguntaron -judíos y cristianoscómo pudo vencer fuegos tan soberanos cuando no manejaba ni sus pies ni sus manos, y quién pudo dejarle todos sus miembros sanos.

El niño respondió con palabra excitada:

“La señora que estaba en la silla dorada 
con su hijo en los brazos sobre el altar posada, ella me defendió y no me pasó nada."

Comprendieron entonces que la señora ésta era Santa María, siempre a defensa presta. Entonáronle laudes. Le hicieron rica fiesta y en su honor escribieron el milagro de la Gesta.

Tomaron al judío, al falso y desleal que a su pequeño hijo hiciera tanto mal; le ligaron las manos con un fuerte dogal y lo echaron al fuego de su horno infernal.

Menos demoraría contar unos "pepiones" que lo que demoró en convertirlo en carbones. No decían por su alma si salmos ni oraciones, sino que mil injurias y otras mil maldiciones.

Decían mil maleficios y hacían mala ofrenda, y en vez de PATER NOSTER: "Quien tal hizo, tal prenda, que de su compañía el Señor nos defienda y que le dé al Demonio su fortuna y hacienda”.

Así es Santa María, la de la gracia plena, capaz de darnos premios como de darnos pena: a los buenos, el trigo; a los malos, la avena. Los unos van en la Gloria; los otros, en cadena.

Quien le presta servicio gana buenaventura; quien no la sirve a Ella, nació con desventura. 
Estos ganan rencor; aquellos, su ternura.

Los buenos y los malos revelan su factura.

Quienes la despreciaron y nunca la sirvieron, ganaron sus favores apenas lo pidieron.

Jamás repudió Ella a quienes la quisieron, ni dio réplica airada a los que mal le hicieron.

Para probar lo dicho tal como lo creemos, escuchad otro ejemplo de aquellos que leemos.

Mientras más los contemos, mejor lo apreciaremos.

De buscarle pesares aún más nos aguardaremos. 